\title{
The use of linked DNA polymorphisms for genotype prediction in families with Duchenne muscular dystrophy
}

\author{
P S HARPER*, T O'BRIEN*, J M MURRAY* $\uparrow$, K E DAVIES $\dagger$, P PEARSON + , \\ AND R WILLIAMSON†
}

From *the Section of Medical Genetics, Department of Medicine, Welsh National School of Medicine, Heath Park, Cardiff; the Department of Biochemistry, St Mary's Hospital Medical School, London; and +the Department of Human Genetics, State University of Leiden, The Netherlands.

SUMmARY Two DNA restriction fragment length polymorphisms show genetic linkage to the Duchenne muscular dystrophy locus on the short arm of the $\mathrm{X}$ chromosome. Examples are given of families in which these polymorphisms can be used in the prediction of genotype for this disorder.

Neither the nature of the gene defect nor the primary abnormality of the gene product responsible for Duchenne muscular dystrophy (DMD) is known at present, a situation which applies equally to all the human muscular dystrophies. Heterozygote detection is feasible to a limited extent using raised serum creatine kinase and other approaches, ${ }^{1}$ but a combination of $\mathrm{X}$ chromosome inactivation and the variability of available tests means that a considerable proportion of carriers cannot be detected reliably. Antenatal diagnosis is similarly not possible at present. ${ }^{2}$

We have recently applied recombinant DNA techniques to localise the DMD gene to a small region of the $\mathrm{X}$ chromosome. We have shown linkage between the DMD locus and a cloned DNA sequence $(\lambda \mathrm{RC})$ from an $\mathrm{X}$ chromosome gene library, ${ }^{34}$ while a second DNA sequence (L1.28) also shows linkage at a comparable distance. ${ }^{5}$ The two probe sequences are located on the short arm of the $X$ chromosome and appear to flank the DMD locus, with approximate distances of 15 and 13 centiMorgans respectively from it (fig 1). Both probes show restriction fragment length polymorphisms (RFLPs) with the enzyme TaqI. Such polymorphisms are usually the result of changes in the DNA sequence, and cause fragments of different lengths to be generated after restriction enzyme digestion, which can be distinguished after hybridisation with radioactive DNA probes. Both the RFLPs used in this study follow Mendelian X linked inheritance, the frequency of heterozygotes being $22 \%$ for $\lambda R C 8$ and $45 \%$ for $L 1.28$.

Received for publication 1 March 1983. Accepted for publication 10 March 1983.

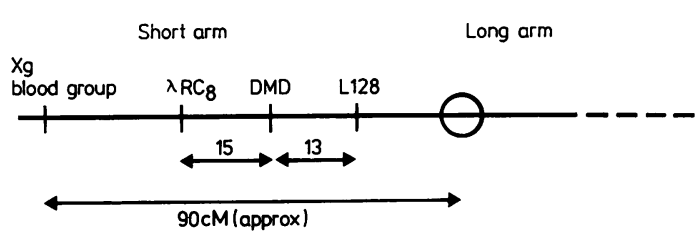

FIG 1 Diagram of the short arm of the $X$ chromosome, showing the approximate linkage relationships of the DMD locus and the two linked DNA probes.

While these two probes are not sufficiently close to the DMD locus to be used alone for the direct study or prediction of the DMD gene, they demenstrate the potential of using recombinant DNA sequences for carrier detection and, in certain circumstances, are likely to be of clinical use. We give examples here of specific situations where they can be applied, illustrated by families that we have studied.

\section{Methods}

The laboratory techniques involved have been $\tilde{O}$ described in detail elsewhere. ${ }^{34}$ DNA is isolated $\underset{\omega}{N}$ from the leucocytes in a 10 to $20 \mathrm{ml}$ sample of venous blood. After digestion with the restriction enzyme 0 TaqI, electrophoresis, and Southern transfer to a $\frac{2}{\Phi}$ nitrocellulose filter, the DNA is hybridised with the $\stackrel{0}{?}$ appropriate radiolabelled probe. ${ }^{6}$ The polymorphism 0 is detected by autoradiography as a specific band $\vec{P}$ pattern, each allele being represented by a band at a $\triangle$ position corresponding to the size of the restriction $\vec{\otimes}$ fragment; heterozygotes show both bands. 
EXAMPLE 1. FAMILY INFORMATIVE FOR BOTH POLYMORPHISMS (FIG 2)

In this family the mother (3) is not only an obligatory carrier for DMD, but is heterozygous for both DNA polymorphisms. She has transmitted the DMD with the ' 2 ' form of each polymorphism and, since the markers flank the DMD locus, a further male child with the same genotype would be expected to be affected, while one with the genotype B1, C1, should be unaffected, except in the unlikely (probability $2 \%$ ) event of a double cross-over. A similar prediction (taking into account the father's genotype) could be made for the carrier state of a female child. It should be noted, however, that these relatively accurate predictions assume that the mother does indeed carry the DMD gene on the same $X$ chromosome as the B2 and C2 alleles. In this particular family this is likely but not absolutely certain, since the maternal grandfather (1) is dead. The error in prediction, based on the observed gene frequency of $13 \%$ for $\lambda \mathrm{RC} 8$ allele $\mathrm{B} 2$, is increased to around $3 \%$, compared with around $2 \%$ for a family where the 'phase' is known with certainty.

EXAMPLE 2. FAMILY INFORMATIVE FOR ONE POLYMORPHISM ( $\lambda$ RC 8 ); MOTHER'S PHASE KNOWN (FIG 3)

In this family we can see from the pedigree that the mother (4) inherited the B1 allele from her mother along with the DMD gene, while the B2 allele was inherited with the normal $\mathrm{X}$ chromosome from her father. In the third generation the DMD and B1 alleles have again been transmitted to the affected son (6) while the daughter (7), having inherited the B2 allele from her mother, would be expected not to have the DMD allele unless crossing-over has

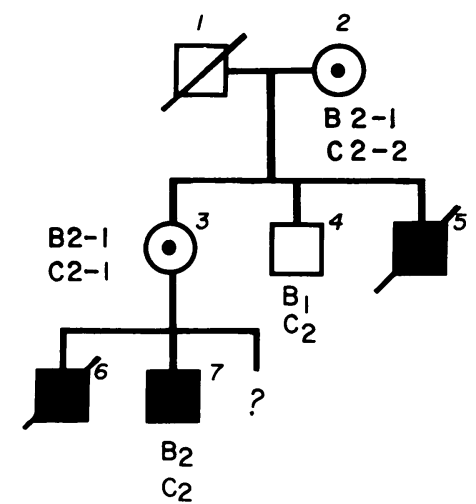

FIG $2 A$ DMD fanily informative for both RFLPS.

$B$ and $C$ refer to the alleles for $\lambda R C 8$ and $L 1.28$ respectively, $B I$ and $C 1$ representing the more common ailele, $B 2$ and $C 2$ the less common.

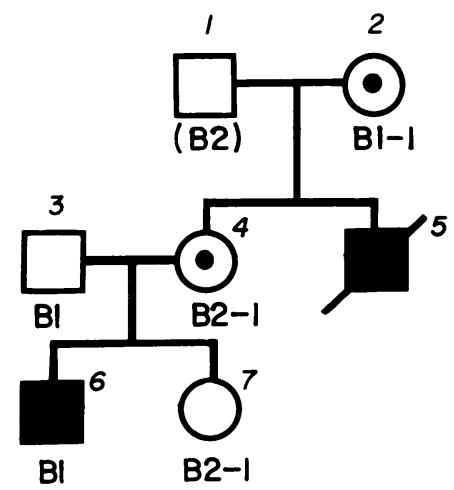

FIG $3 A D M D$ family informative for $\lambda R C 8$. Symbols as in fig 2. Parentheses indicate the inferred genotype of an unavailable person.

occurred. Her genetic risk of $50 \%$ of being a carrier can thus be reduced to $15 \%$. Precisely the same risk for being affected could be given for further male offspring of (4) who had inherited the B2 allele.

EXAMPLE 3. FAMILY INFORMATIVE FOR L1.28 ALONE; MOTHER'S PHASE KNOWN (FIG 4)

In this family the mother (4) has transmitted the DMD gene to her affected son along with the C2 allele. We know also that she received the two together from her mother, since her sister (5) has C1-1 genotype, necessitating the grandfather (2) being $\mathrm{C}$. The two daughters ( 7 and 9 ) each have a prior risk of $50 \%$ of carrying the DMD gene, but their different genotyping raises the risk in the case of 7 to $87 \%$, while for 9 it is reduced to $13 \%$.

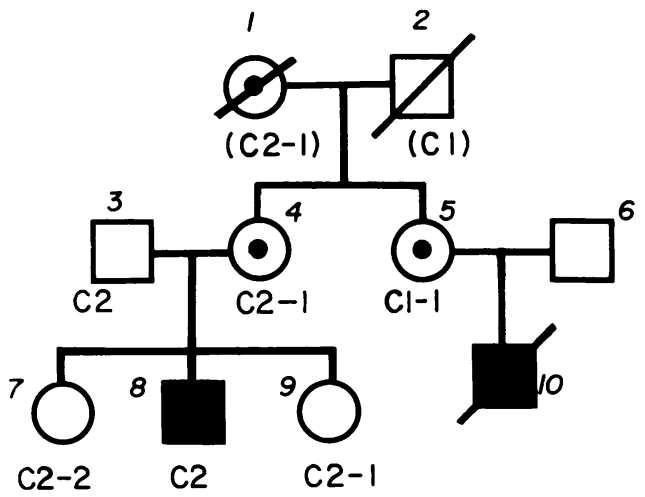

FIG 4 A DMD family informative for L1.28. Symbols as in figs 2 and 3. 
COMBINED USE OF DNA PROBE DATA AND EXISTING CARRIER DETECTION METHODS For families informative for only one of these RFLPs, the margin of error resulting from cross-over at meiosis is too great for the information to be definitive in isolation. However, when combined with data from existing tests for carrier status, a much more accurate prediction may be obtained. The family shown in fig 3 again provides an example of this situation. Creatine kinase testing on subject 7 gave a result of $46 \mathrm{IU} / 1$ (mean of three separate determinations), representing a probability of 0.11 of being a carrier according to our own laboratory range. Combining this information with the previous risk of $0.15(15 \%)$ from linkage data gives a final risk of $0 \cdot 11 / 0.89 \times 0 \cdot 15 / 0 \cdot 85=2 \cdot 2 \%$.

\section{Discussion}

In our studies to establish genetic linkage for DMD, we have relied entirely on persons whose genotype is known with certainty and have omitted possible carriers from the analyses. ${ }^{4}$ However, now that linkage is established we can use our gene probes in predicting the genotype of those subjects where it is not certain on genetic grounds.

The margins of error involved for these probes, which are still a moderate distance from the DMD locus, make this approach inappropriate at present for antenatal diagnosis. For carrier detection in female relatives, the use of linkage data in conjunction with more established techniques such as creatine kinase is likely to allow more definite predictions to be made in those persons whose carrier status is at present indeterminate. Clearly, the development of more closely linked probes, in progress at present, will reduce the error, while the detection of additional polymorphisms at high frequency in the population will increase the proportion of informative families.

A particular advantage of using DNA polymorphisms is the lack of ambiguity resulting from $\mathrm{X}$ chromosome inactivation, which has seriously hindered all carrier tests based on phenotype. It is also possible to follow both polymorphisms described above using DNA from chorionic villi (Elles and Williamson, unpublished data), a technique already established for the haemoglobinopathies. ${ }^{8}$
This work was supported by the Muscular Dystrophy Group of Great Britain, the Muscular Dystrophy Association of America, The Medical Research Council, and the Cystic Fibrosis Research Trust.

\section{References}

1 Harper PS. Carrier detection in Duchenne muscular dystrophy: a critical assessment. In: Shotland DL, ed. Disorders of the motor unit. New York: Wiley, 1982: $821-46$.

2 Emery AEH. Duchenne muscular dystrophy: genetic aspects. Br Med Bull 1980;36:117-22.

3 Davies KE, Young BD, Elles RG, Hill ME, Williamson R. Cloning of a representative genomic library of the human $\mathrm{X}$ chromosome after sorting by flow cytometry. Nature $1981 ; 293: 374-6$.

4 Murray JM, Davies KE, Harper PS, et al. A cloned DNA sequence on the short arm of the $X$ chromosome: linkage relationship to Duchenne muscular dystrophy. Nature 1982;300:69-71.

5 Davies KE, Pearson PL, Harper PS, et al. Linkage analysis of two cloned DNA sequences flanking the Duchenne muscular dystrophy locus on the short arm of the human X chromosome. Nucleic Acids Res 1983;11 : 2303-12.

6 Southern EM. Detection of specific sequences among DNA fragments separated by gel electrophoresis. $J \mathrm{Mol}$ Biol 1975;98:503-17.

7 Williamson R, Eskdale J, Coleman DV, Niazi N, Loeffler FE, Modell B. Direct gene analysis of chorionic villi: a possible technique for first-trimester antenatal diagnosis of haemoglobinopathies. Lancet 1981 ;ii:1125-7.

8 Old JM, Ward RHT, Petrov M, Karogozlu F, Modell B, Weatherall DJ. First trimester fetal diagnosis for haemoglobinopathies: three cases. Lancet 1982;ii:1413-6.

Correspondence and requests for reprints to Professor P S Harper, Section of Medical Genetics, Welsh National School of Medicine, Heath Park, Cardiff CF4 4XN.

\section{Note added in proof}

Since this paper was written further data have been analysed, suggesting a most likely distance of $17 \mathrm{cM}$ between the DMD locus and each probe. The precise distances involved, and thus the accuracy of genotype prediction, will depend on further work in progress. 